\title{
Determinant of emergency contraceptive practice among female university students in Ethiopia: systematic review and meta- analysis
}

Rekiku Fikre ${ }^{1 *}$, Belay Amare ${ }^{1}$, Alemu Tamiso ${ }^{2}$ and Akalewold Alemayehu ${ }^{2}$

\begin{abstract}
Introduction: Despite Ethiopia's government's commitment to alleviating unwanted pregnancy and unsafe abortion by increasing holistic reproductive health service accessibility, the rate of unwanted pregnancy among female students in the universities is distressing and becoming a multisectoral concern. Therefore, this systematic review aimed to assess the prevalence and determinant of emergency contraceptive practice among female university students in Ethiopia.

Result: The overall pooled prevalence of emergency contraceptive practice among female university students in Ethiopia was 34.5\% [95\% Cl [20.8, 48.2\%]. The pooled odds ratio showed that positive association between practice of emergency contraceptives with age of the students [OR, 0.19; 95\% Cl: 0.04, 0.98, $P=0.05]$ Previous contraceptive methods use [OR, $0.22 ; 95 \% \mathrm{Cl}: 0.12,0.40, P=0.0001]$, Marital status [OR, 0.09; $95 \% \mathrm{Cl}: 0.02,0.40, P<0.002]$ and knowledge [OR, $0.12 ; 95 \% \mathrm{Cl}: 0.04,0.37, P<0.0003]$.

Conclusion: The practice of emergency contraceptives among university female students was $34.5 \%$ and explained by knowledge, age, previous use of contraceptive methods and marital status.
\end{abstract}

Keywords: Emergency contraceptive, Ethiopia, Female university students, Systematic review, Meta-analysis

\section{Background}

Worldwide, 250 million pregnancies are occurred annually, and $11 \%$ of pregnancy are accounted by adolcent then, one third of them are untended and $20 \%$ of the pregnancy ended up with induced abortion $[1,2]$.

The Young generation was facing multiple reproductive health problems and among them, unintended pregnancy poses a major contest in developing countries. Due to economic dependability and lack of friendly approach in the facility, young women prone to end

\footnotetext{
* Correspondence: frekiku@yahoo.com

'Department of Midwifery, Hawassa University, College of Medicine and Health Sciences, P.O. Box 1560, Hawassa, Ethiopia

Full list of author information is available at the end of the article
}

unwanted pregnancy through unsafe conditions which take the highest share for morbidity and mortality compared with adult women [3].

Around 80 million unintended pregnancies occurred in the developing world in 2012, resulting in 40 million abortions and 10 million miscarriages [4]. According to the World Health Organization report every year, nearly 5.5 million African women have unsafe abortions. Moreover, $59 \%$ of all unsafe abortions in Africa are among young women aged $15-24$ years [5].

In the Ethiopian context, Emergency contraceptives are not part of family planning methods but used as an emergency contraceptive by women when they encountered different situations that predispose them for 
unwanted pregnancy [6]. Even though the practice of emergency contraceptives was low in Ethiopia, Emergency contraceptives can reduce the risk of unintended pregnancy by 75 to $99 \%$ if it is taken within three days of sexual intercourse [7, 8]. The impact of emergency contraceptives on the prevention of unplanned pregnancy and to avoid unsafe abortion which is a treat for young women were deceived [9].

Several studies revealed that the practice of emergency contraceptive is different from one country to another. The practice of emergency contraceptives was (28\%) among South African university students [10], (7.4\%) in Cameroon [11] and (5.4\%) in Nigeria [12].

The Ethiopian demographic health survey 2016 (EDHS 2016) report showed that contraceptive prevalence rate among Ethiopian women aged 15-49 is 36\%, however, the practice of emergency contraceptives among sexually active unmarried women is low $4 \%$ [13].

Planned Pregnancy is a period of transition from childhood to an adult but if it was unplanned, the life of young women could have changed in many ways making them vulnerable to poverty and exclusion, and their health often suffers [14].
A study showed that the practice of emergency contraceptives in Ethiopia is below 10\% [15, 16]. The magnitude of emergency contraceptive utilization practice among female University students in Ethiopia ranges from lowest $4.9 \%$ to the highest $78 \%[17,18]$.

Therefore, this study aims to summarize evidence of emergency contraceptive practice among female university students in Ethiopia.

\section{Methods}

\section{Search strategies and quality appraisal}

The protocol for this systematic review and metaanalysis has been enrolled in the International Prospective Register of systematic reviews (PROSPERO). The methodology of this systematic review and meta-analysis was developed by following the Preferred Reporting Items for Systematic Reviews and Meta-Analyses (PRIS MA) Additional file one.

The authors conducted systematic literature searches from the authentic major electronic databases such as MEDLINE, PubMed, EMBASE, Emcare, CINAHL (EBSCOhost), Web of Science, Scopus, Poplin, and Google Scholar. Also, the hand (manual) accomplished to retrieve

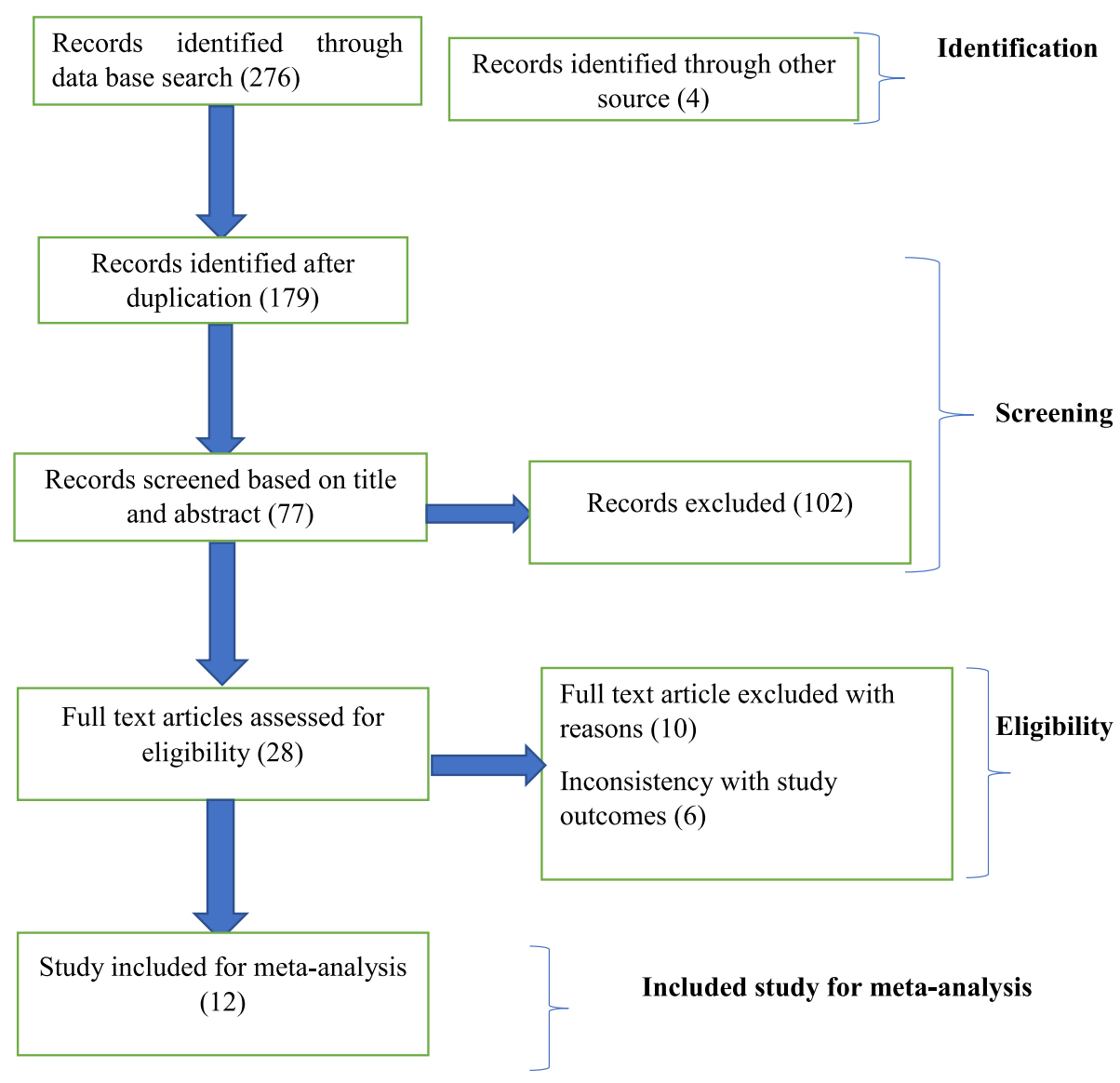

Fig. 1 Description of a schematic presentation of the PRISMA flow diagram to select and include studies, 2020 


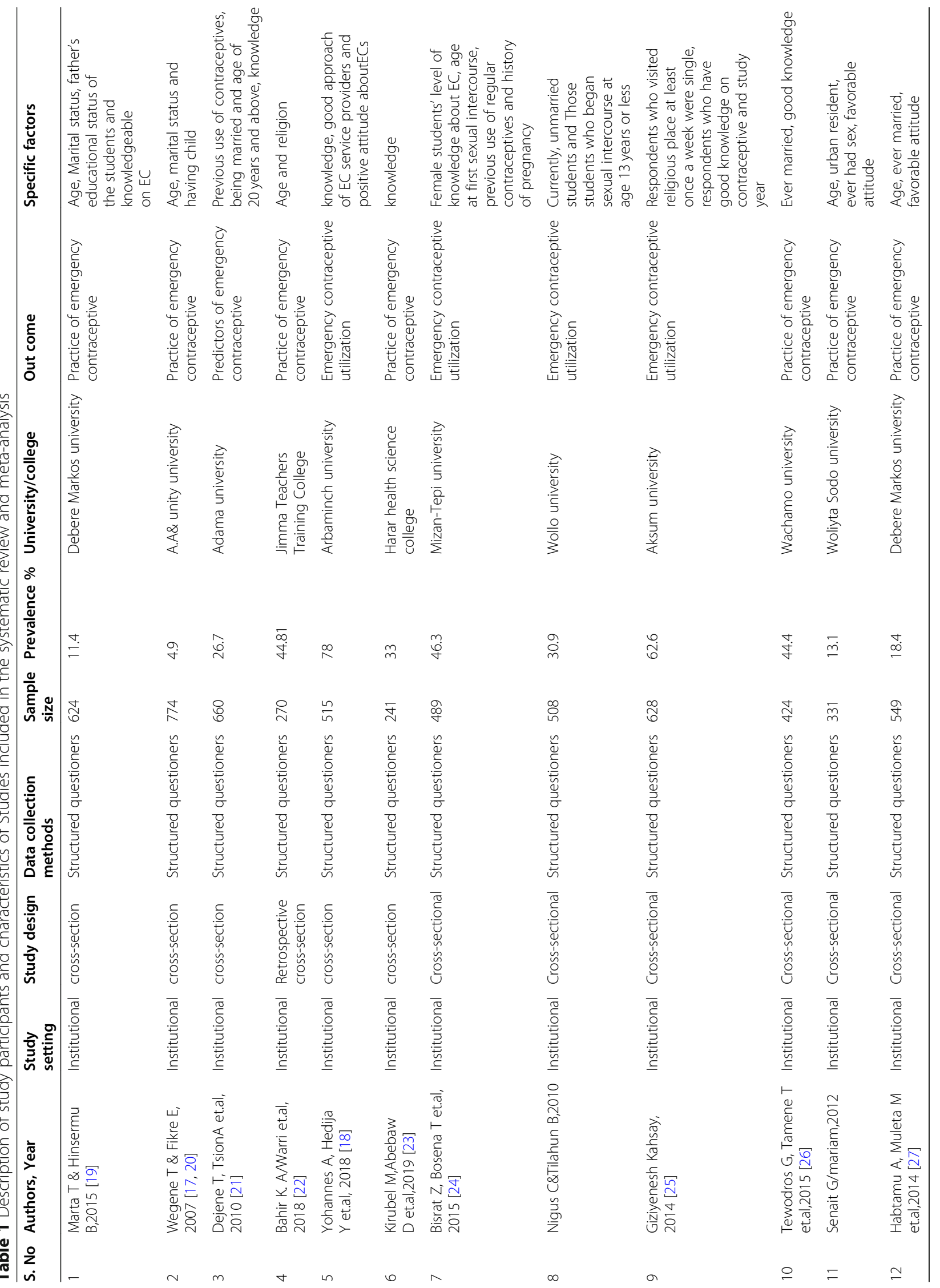




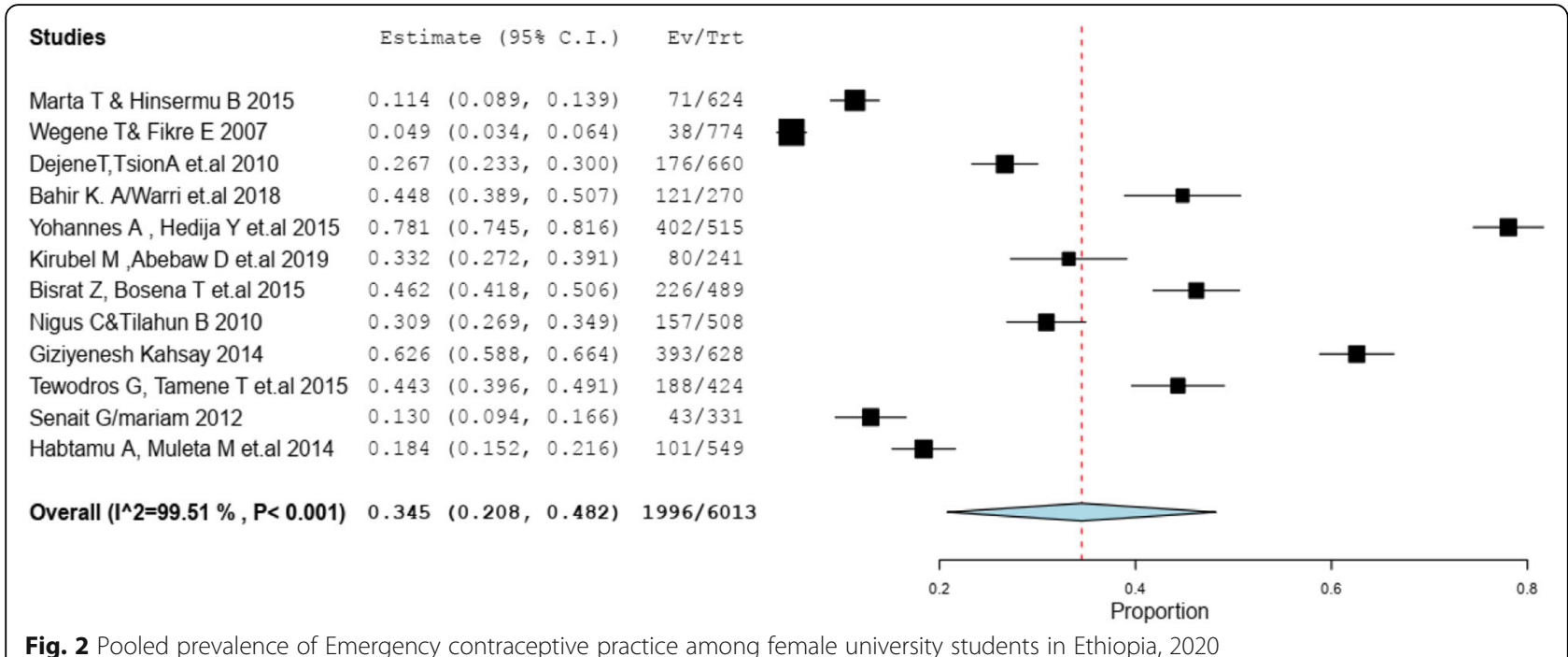

unpublished studies and gray literature. We used $\mathrm{MeSH}$ terms, key terms, and search engines by extracting from the review questions for all the searches. The search strategy included "Predictors" OR "Determinants" OR "Related factors" OR "Factors" AND "Emergency contraceptive practice" OR "Emergency contraceptive utilization" OR "Emergency" AND "Practice" AND "Ethiopia". Both authors constructed the search strings (RF and AA). The overall search result was compiled using EndNote X9 citation manager software Additional file two.

Later, articles were screened through a careful reading of the title and abstract. The two authors screened and evaluated the studies independently. The titles and abstracts of studies that mentioned the outcomes of the review were considered for further evaluation to be included in the systematic review and meta-analysis. Then the full-texts of the retained studies were further evaluated based on the quality of their objective, methods, participants/population, and key findings. The authors (RF, AT, and BA) independently evaluated the quality of the studies included against the Joanna Briggs Institute (JBI) critical appraisal tool checklists.
In case of disagreement between the quality assessment results of the two authors, the differences were resolved by consensus for inclusion. The overall study selection process is presented using the PRISMA statement flow diagram (Fig. 1).

\section{Data extraction and analysis}

Findings from the selected studies were extracted and stored using data extraction template prepared on Microsoft Word and then to Excel (2016), followed by extraction of important data based on study characteristics (first author, year of publication, study design, and outcome of interest) by the two authors independently. Meta-analysis was conducted using OpenMeta and CMA version 2 software to compute the pooled prevalence and factors associated with the emergency contraceptive practice.

\section{Heterogeneity and publication bias}

Heterogeneity between the included studies was examined using the $I^{2}$ statistic. A meta-analysis of observational studies was conducted, based on recommendations made

\begin{tabular}{|c|c|c|c|c|c|c|c|c|c|c|}
\hline \multirow{2}{*}{$\begin{array}{l}\text { Study or Subgroup } \\
\text { Bahir K. AMvarri et.al,2018 }\end{array}$} & \multicolumn{2}{|c|}{$\$ 20$ year } & \multicolumn{2}{|c|}{$>20$ year } & Weight & $\begin{array}{c}\text { Odds Ratio } \\
\text { M-H, Random, } 95 \% \mathrm{Cl}\end{array}$ & \multicolumn{4}{|c|}{$\begin{array}{c}\text { Odds Ratio } \\
\mathrm{M}-\mathrm{H}, \text { Random, } 95 \% \mathrm{Cl}\end{array}$} \\
\hline & 11 & 72 & 29 & 59 & $20.5 \%$ & $0.19[0.08,0.42]$ & & $\longrightarrow$ & & \\
\hline DejeneT,TsionA et.al,2010 & 6 & 220 & 25 & 430 & $20.2 \%$ & $0.45[0.18,1.12]$ & & & & \\
\hline Habtamu A, Muleta M et.al,2014 & 231 & 299 & 13 & 19 & $20.0 \%$ & $1.57[0.57,4.28]$ & & & & \\
\hline Marta T \& Hinsermu B,2015 & 63 & 426 & 5 & 10 & $19.1 \%$ & $0.17[0.05,0.62]$ & & & & \\
\hline Wegene T\& Fikre E,2007 & 7 & 772 & 23 & 52 & $20.2 \%$ & $0.01[0.00,0.03]$ & 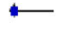 & & & \\
\hline Total $(95 \%$ Cl) & & 1789 & & 570 & $100.0 \%$ & $0.19[0.04,0.98]$ & & & & \\
\hline Total events & 318 & & 95 & & & & & & & \\
\hline $\begin{array}{l}\text { Heterogeneity: Tau }{ }^{2}=3.20 ; \mathrm{Ch}^{2}= \\
\text { Test for overall effect: } Z=1.99(\mathrm{P}\end{array}$ & $\begin{array}{l}57.01, \mathrm{df}= \\
0.05)\end{array}$ & $=4(\mathrm{P}$ & 0.00001 & $1 ; 1^{2}=$ & $93 \%$ & & 0.01 & 0.1 20 ye & $1>20$ year ${ }^{10}$ & $100^{\circ}$ \\
\hline
\end{tabular}

Fig. 3 Association between the age of female university students with the emergency contraceptive practice among female students in Ethiopia 2020 


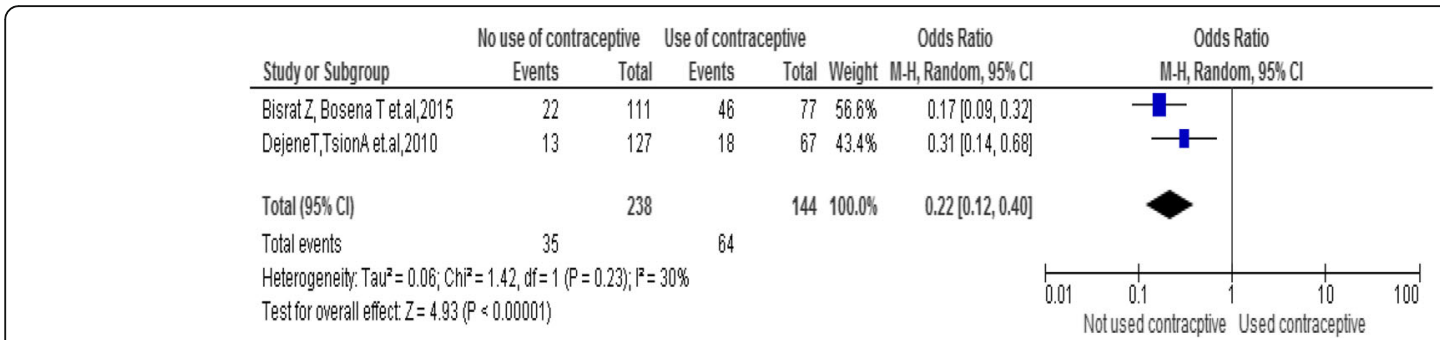

Fig. 4 Association between a history of contraceptive methods use with the emergency contraceptive practice among female university students in Ethiopia, 2020

by Higgins et al. (An $\mathrm{I}^{2}$ of $75 / 100 \%$, suggesting considerable heterogeneity).

\section{Result}

\section{Review studies}

A total of 276 articles were identified through the major electronic databases and other relevant sources search from January $1 / 2020$ to Febraruary1/2/2020. From all identified studies, 179 articles were removed due to duplication while 77 studies were reserved for further screening. Of these, 102 were excluded after being screened according to titles and abstracts. Of the 28 remaining articles, 16 studies were excluded due to inconsistency with the inclusion criteria set for the review. Finally, 12 studies that fulfilled the eligibility criteria were included for the systematic review and metaanalysis. General characteristics and descriptions of the studies selected for the meta-analysis were outlined in (Table 1).

\section{Prevalence of emergency contraceptive practice}

The pooled approximation of the magnitude of emergency contraceptive practice in Ethiopia was 34.5\% [95\% CI [20.8, 48.2\%] (Fig. 2).

\section{Determinants of emergency contraceptive practice}

The results of this review have shown determinants significantly associated with emergency contraceptive practice in Ethiopia were, Age [OR, 0.19; 95\% CI:0.04, $0.98, P=0.05]$ Previous contraceptive method use [OR, 0.22; 95\% CI: 0.12, 0.40, $P=0.000001]$, Marital status [OR, 0.09; 95\% CI: 0.02, 0.40, $P<0.002$ ] and knowledge [OR, 0.12; 95\% CI: 0.04, 0.37, $P<0.0003$ ]. The review also verified that attitude was not a significant predictor of emergency contraceptive practice [OR, $0.61 ; 95 \% \mathrm{CI}$ : $0.00,136.12, P<0.86]$.

\section{Age of the students}

The findings of the review indicated a significant association between age and the practice of emergency contraceptives. Female university students age less than 20 were 0.19 times less likely to practice emergency contraceptive compared to students who had age greater than 20 [OR $=0.19$; 95\% CI: 0.04, 0.98, $P=0.05$ ]. Heterogeneity test indicated I $2=93 \%$, (Fig. 3 ).

\section{History of contraceptive method use}

The findings of the review indicated a significant association between history of contraceptive method use and emergency contraceptive practice. Students who hadn't have history of contraceptive methods use were 0.22 times less likely to emergency contraceptive practice compared to students who had a history of contraceptive methods use [OR $=0.22$; 95\% CI: $0.12,0.40, P=0.0001]$. Heterogeneity test indicated I $2=30 \%$, (Fig. 4).

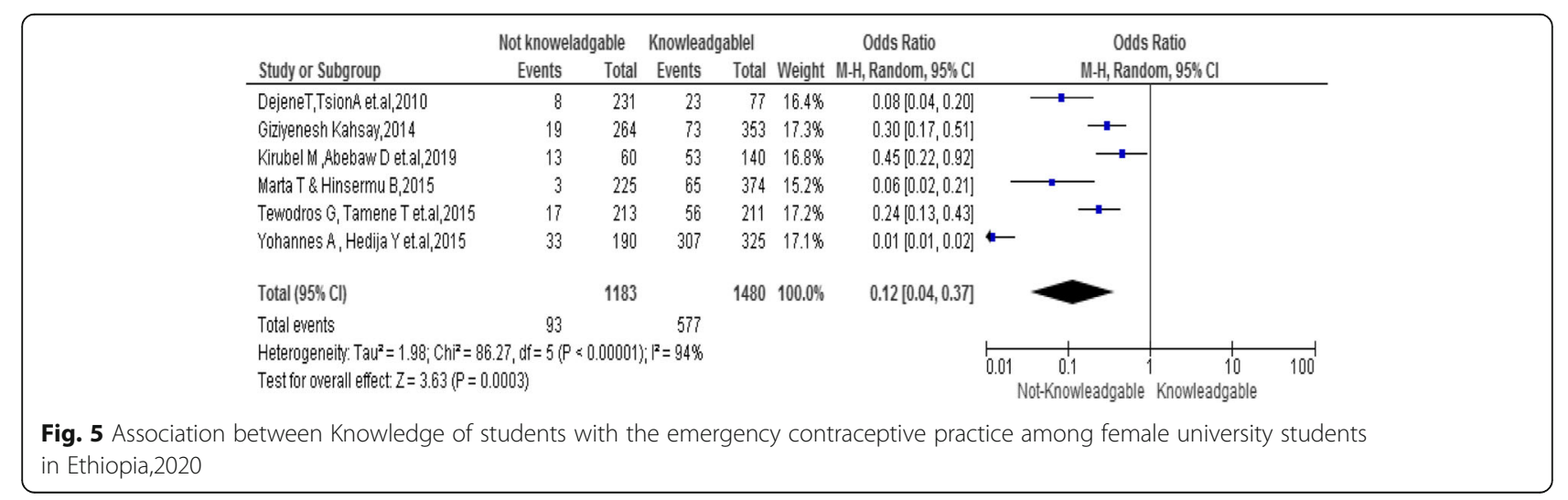




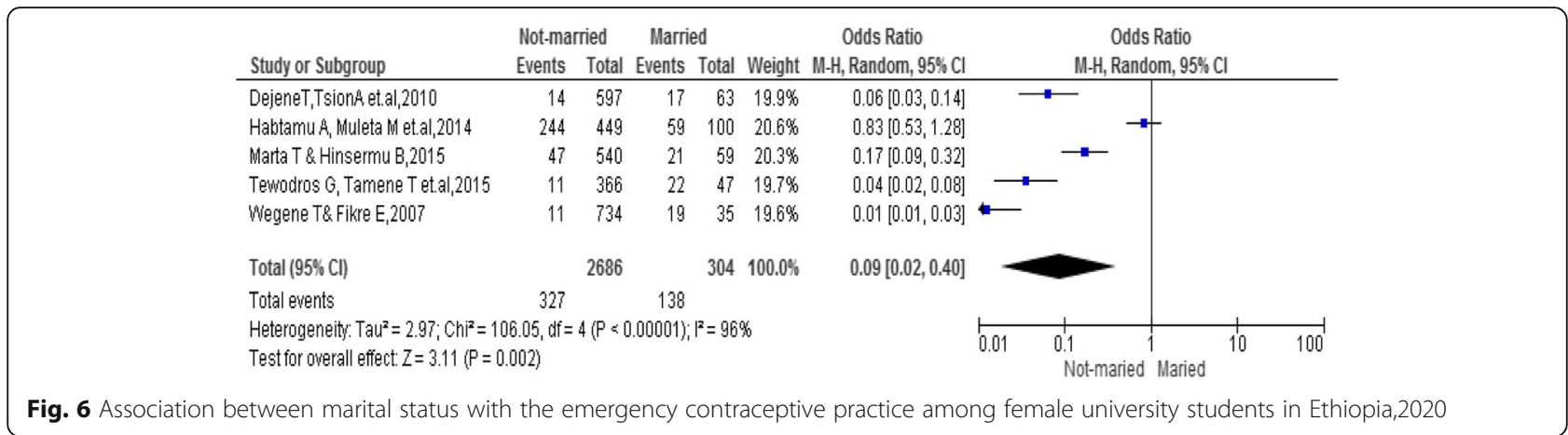

\section{Knowledge of the student}

This review demonstrated that there was significant association between students' knowledge and emergency contraceptive practice in the random model [OR, 0.12; 95\% CI: $0.04,0.37 ; P=0.0003]$. Students who were notknowledgeable were 0.12 times less likely to practice emergency contraceptives as compared to students who knew emergency contraceptives. But considerable heterogeneity was found too high $\left(\mathrm{I}^{2}=94 \%\right)$, hence the random effect model was assumed in the analysis. Sensitivity analysis was done but did not bring significant change in the overall summary results of OR (Fig. 5).

\section{Marital status}

Being married was significantly associated with the emergency contraceptive practice, the odds of emergency contraceptive practice were high among married as compared to others [OR, 0.09; 95\% CI: 0.02, 0.40, $P=$ 0.002]. Not-married students were 0.09 times less likely to practiced emergency contraceptives as compared to Married (Fig. 6).

\section{The attitude of the students}

The results of the review presented there was no statistically significant association between attitudes of students and emergency contraceptive practice [OR, 0.61; 95\% CI: $0.00,136.12, P<0.86]$. The heterogeneity test was too high and the $\mathrm{I}^{2}$ value was $93 \%$. However, the investigators considered a random effect model for the analysis (Fig. 7).

\section{Publication bias}

To check publication bias among the included studies for the meta-analysis, funnel plot and Egger's test were carried out (Figs. 8 and 9).

\section{Discussion}

Practicing emergency contraceptive to overcome unwanted pregnancy is a vital role, perhaps its practice should be under cautions. This comprehensive study provides potted information on inclusive determinants that limit the practice of emergency contraceptives in female university students in Ethiopia.

In this review, a total of 12 studies were included and all studies are collected primary data to assess the practice of emergency contraceptives. One of the breaches identified during this review was data were collected from students; which may be subject to recall bias. Our analysis revealed that the practice of students towards emergency contraceptives across the universities shows differences, in Arbaminch university 78\% [18], Aksum university 62.8\% [25] and Addis Ababa university 4.9\% [17]. The possible reason for this discrepancy may be due to that both Arbaminch and Aksum university were tourist sites so that students might be exposed to unprotected sexual intercourse to overcome their soceconomic problem and in Addis-Ababa the awareness of

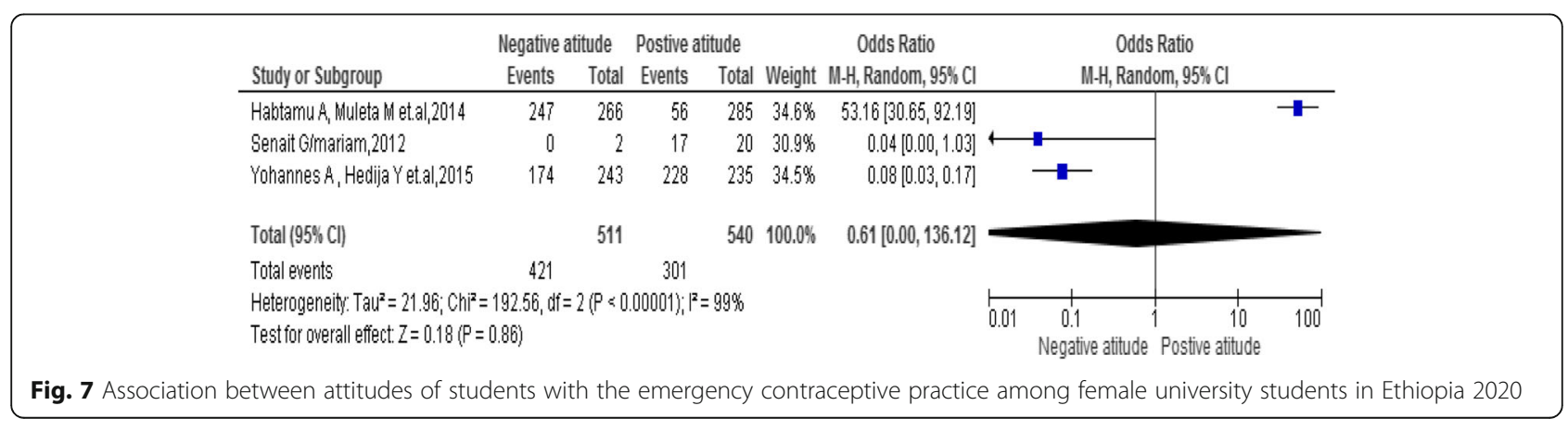




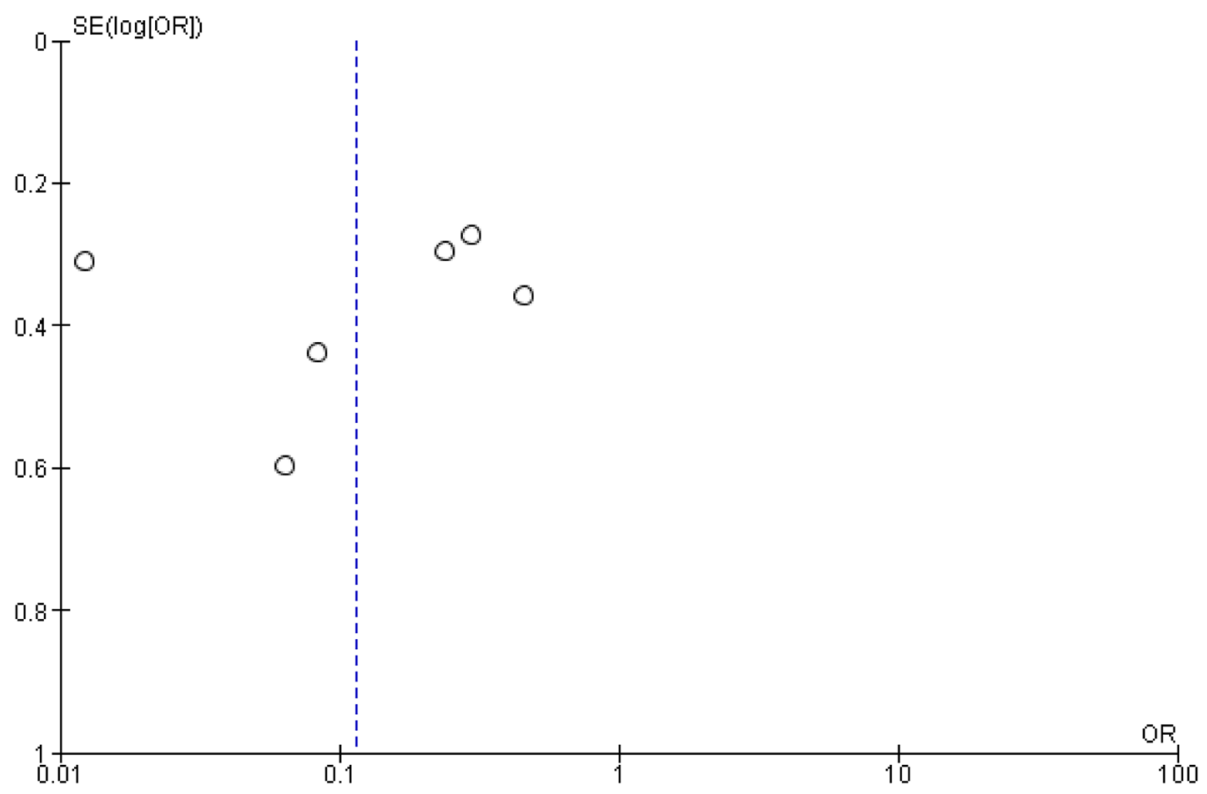

Fig. 8 Publication bias on the knowledge of the students

the students was better due to the presence of many institutes in the compound over reproductive health.

This systematic and meta-analysis revealed that the overall prevalence of emergency contraceptive practice during the period studied in Ethiopia was 34.5\% [95\% CI $[20.8,48.2 \%]$. This study is higher than findings from South African university students, 28\% [10], Cameroon, 7.4\% [11] Kenya, 20.2\% [28], Kampala, 7.4\% [29] Hong Kong, $12.9 \%$ [30]. The variation could be due to easy availability of the drug without prescriptions but lower than a study conducted in Federal Polytechnic Kaduna, Nigeria 38\% [12], Ghana 41\% [31]. The possible reason for this might be lack of awareness, lack of youthfriendly approach of the providers with in university clinics, less sexual experience and also poor knowledge of the students in all-rounded reproductive health issues.

In this review and meta-analysis, we found several determinants that have a significant association with emergency contraceptive practice in Ethiopia. In this review and meta-analysis, the emergency contraceptive practice

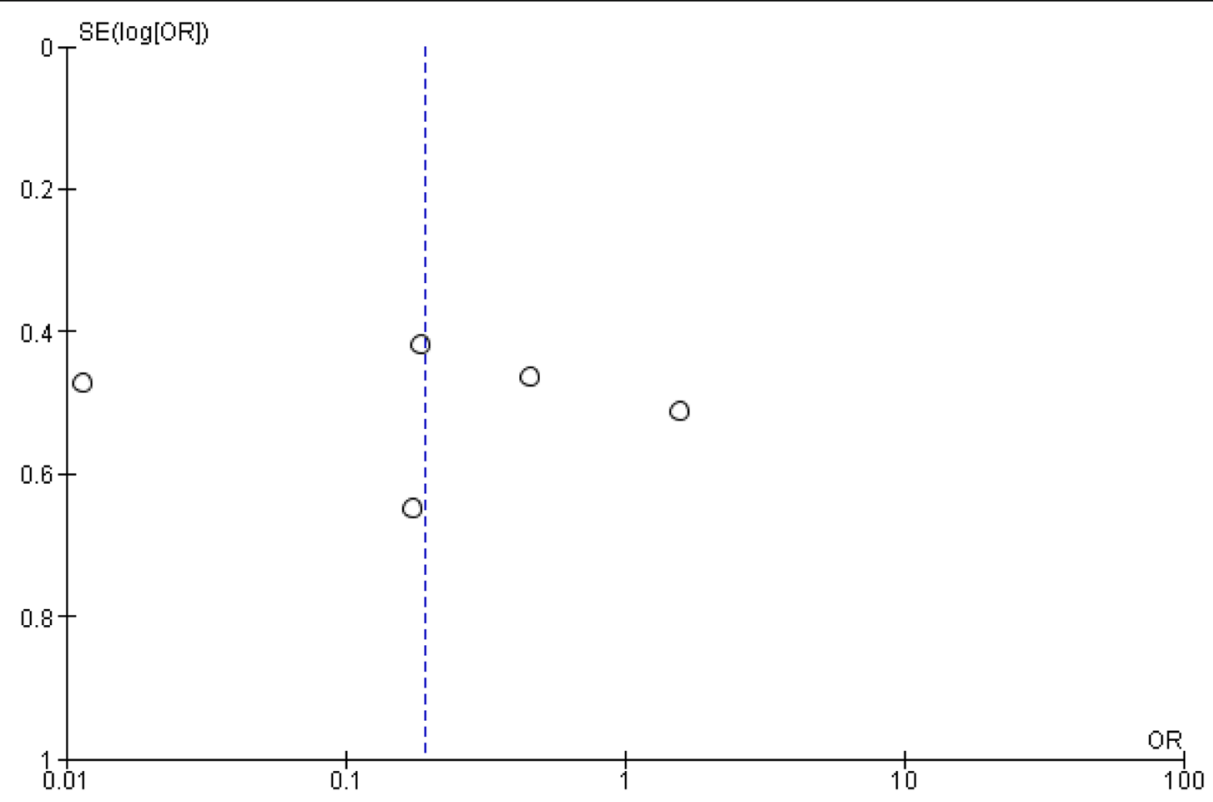

Fig. 9 Publication bias on the age of the students 
was positively associated with work age, the previous history of contraceptive method uses, knowledge and marital status. The attitude was no association with emergency contraceptive practice.

The review revealed that students age less than 20 were less likely to practice emergency contraceptives [19-22, 27]. This finding was consistent with the finding of a study conducted in Kenya [28]. This might be related to, less exposure for sexual experience due to less adaptiveness for the environment and less sexual experience of their peer.

History of contraceptive method use is determinant that helps students to practice emergency contraceptives $[21,24]$. This is because those students who have a history of contraceptive method use have better knowledge and awareness when compared with their counterparts.

Additionally, not-knowledgeable about emergency contraceptives was among the determinants contributing to the poor practice of emergency contraceptives in Ethiopia [19, 21, 23, 25, 26, 32]. This finding was similar to different studies $[33,34]$ This might be due to lack of awareness and lack of information.

The review revealed that students who hadn't married were less likely to practice emergency contraceptives [19-21, 26, 27]. This finding was in line with Demographic and Health Survey reports of 21.7, 15, 11 , and 10\%, in Albania, Ukraine, Kenya, and Colombia, respectively [33, 34]. The possible reason for this might be less risk-taking behavior, lack of information and awareness.

\section{Conclusion}

The emergency contraceptive practice among female university students in Ethiopia is $34.5 \%$. This leads many students to discontinue their education with a lot of RH problems. So integrated effort is needed within Ethiopian ministry of education, minister of health and with respective higher institutions to avail family planning the course for every stream and need to strengthen reproductive health clinics and arranging service provision youth-friendly to extended the uptake to overcome the problem. Again, different mini-media clubs within institutions also incorporate the issue of $\mathrm{RH}$ as a major concern and take part in updating students. Age, marital status, knowledgeable and history of contraceptive use were among the determinants contributing under-utilization of emergency contraceptives.

\section{Limitation}

Lack of study assessing the situation in all universities found in Ethiopia may have affected the generalizability.

\section{Supplementary information}

Supplementary information accompanies this paper at https://doi.org/10. 1186/s40834-020-00123-8.

Additional file 1: Table S1. Reporting Items for Systematic Reviews and Meta-Analyses: The PRISMA Statement Checklist.

Additional file 2: Table S2. Sample search string for CINHAL database, EBSCOhost Interface. Table S3. Sample search string for Medline database, EBSCO host Interface.

Additional file 3: Table S5. Quality assessment on included studies based on NOS checklist.

\section{Abbreviations}

CMA: Comprehensive meta-analysis; PRISMA: Preferred Reporting Items for Systematic Reviews and Meta-Analyses; JBI: Joanna Briggs Institute

\section{Acknowledgments}

We would like to thank the College of Medicine and Health science, Department of Midwifery Hawassa University (Ethiopia) for non-financial support.

\section{Authors' contributions}

RF, AA, AT, and BA conceived and designed the review. RF, AA and AT carried out the draft of the manuscript and BA is the guarantor of the review. RF, AA, and AT developed the search strings. RF, BA, and AT screened and selected studies. AA and BA extracted the data. RF and AA evaluated the quality of the studies', RF and AA carried out analysis and interpretation. RF, AA, AT, and BA rigorously reviewed the manuscript. All authors read and approved the final version of the manuscript.

\section{Funding}

Not-available.

\section{Availability of data and materials}

If you request, we can avail all the data used.

Ethics approval and consent to participate Not-applicable.

Consent for publication

Not-applicable.

Competing interests

The authors declared that have no competing interests.

\section{Author details}

${ }^{1}$ Department of Midwifery, Hawassa University, College of Medicine and Health Sciences, P.O. Box 1560, Hawassa, Ethiopia. ${ }^{2}$ Hawassa University, College of Medicine and Health Sciences, School of public health, P.O. Box 1560, Hawassa, Ethiopia.

Received: 11 May 2020 Accepted: 10 September 2020

Published online: 05 October 2020

\section{References}

1. WHO and Gutmacher Institute: Facts on induced abortion world-wide 2007, [http://www.searo.who.int/LinkFiles/Publications_Facts_on_Induced_ Abortion_Worldwide.pdf].

2. Mangiaterra $V$, Pendse $R$, Mclure $K$, Rosen J: Adolescent pregnancy. Department of making pregnancy safer (MPS). 2008, WHO MPS note, 1 (1): [http://www.who.int/making_pregnancy_safer/documents/mpsnnotes_2_Ir. pdf].

3. Essential Obstetrics and Gynecology 4th Edition by Symonds MD FRCOG FFPHM FACOG (Hon), E. Malcolm, Symonds DM. Family planning, contraception, sterilization and abortion. p. 347-61.

4. Sedgh G, Singh S, Hussain R. Intended and unintended pregnancies worldwide in 2012 and recent trends. Stud Fam Plan. 2014;45(3):301-14. 
5. World Health Organization. Unsafe Abortion: Global and Regional Estimates of the Incidence of Unsafe Abortion and Associated Mortality in 2003. 5th. Geneva: WHO; 2007. [CrossRef] [Google Scholar].

6. Gracy A, Dunkl K. The subsequent use of post coital contraception in UK. BRJ Fam Plann. 1993;19:218-20 [Google Scholar].

7. Hoque ME, Ghuman S. Knowledge, practices, and attitudes of emergency contraception among female university students in KwaZulu-Natal, South Africa. PLoS ONE. 2012;7(9). https://doi.org/10.1371/journal.pone.0046346 [PMC free article] [PubMed] [CrossRef] [Google Scholar].

8. Lenjisa JL, Gulila Z, Legese N. Knowledge, attitude and practice of emergency contraceptives among ambo university female students, West Showa, Ethiopia. Res J Pharm Sci. 2013;2(11):1-5 [Google Scholar].

9. Schwarz EB, Gerbert B, Gonzales R. Need for emergency contraception in urgent care settings. Contraception. 2007;75:285-8.

10. Kistnasamy EJ, Reddy P, Jordaan J. An evaluation of the knowledge, attitude and practices of south African university students regarding the use of emergency contraception and of art as an advocacy tool. S Afr Fam Pract. 2009;51(5):423-6.

11. Kongnyuy EJ, Ngassa P, Fomulu N, Wiysonge CS, Kouam L, Doh AS. A survey of knowledge, attitudes and practice of emergency contraception among university students in Cameroon. BMC Emerg Med. 2007;7(1):1.

12. Hilary Yacham Zaggi. Contraceptive Knowledge and Practices among Students in Federal Polytechnic Kaduna, Nigeria: An Exploratory Study. Stellenbosch University http://scholar.sun.ac.za 2014.

13. Central Statistical Agency (CSA) (Ethiopia) and ICF. Ethiopia Demographic and Health Survey 2016. Rockville: CSA and ICF; 2016. [Google Scholar].

14. UNFPA. (2017) Adolescent pregnancy. Retrieved 4 July 2017 from: https:// www.unfpa.org/adolescent-pregnancy.

15. Desta B, Regassa N. Emergency contraception among female students of Haramaya University, Ethiopia: surveying the level of knowledge and attitude. Educ Res. 2011;2(4):1106-17.

16. Tajure N. Knowledge, Attitude and Practice of Emergency Contraception among Graduating Female Students of Jimma University, Southwest Ethiopia. Ethiop J Health Sci. 2011;20:2.

17. Wegene T, Fikre E. Knowledge, attitude, and practice on emergency contraceptives among female university students in Addis Ababa, Ethiopia. Ethiop J Health Dev. 2007;21(2):111-6.

18. Yohannes A, Hedija Y, Abel F, Desta G. Prevalence of and Factors Associated with Emergency Contraceptive Use among Female Undergraduates in Arba Minch University, Southern Ethiopia, 2015: A Cross-Sectional Study. Int J Popul Res. 2018;2924308:8

19. Marta T, Hinsermu B. Knowledge, Attitude and Practice on Emergency Contraception and Associated Factors among Female Students of DebreMarkos university, Debre-Markos town, East Gojam Zone, North west Ethiopia. Global J Med Gynecol Obstetrics. 2015;15(1):Version 1.0.

20. Tamire W, Enqueselassie F. Knowledge, Attitude and Practice of Emergency Contraceptives Among Adama University Female Students. Ethiop I Health Dev. 2007;21(2):195-202.

21. Dejene T, Tsion A, Tefra B. Predictors of emergency contraceptive use,central Ethiopia, Adama university. Pan Afric Med J. 2010;7:16.

22. Warri BK, Gurmu TG. Knowledge, attitude and practice of progestin-only emergency contraceptives among female students of Jimma Teachers Training College, Jimma, Ethiopia. Ghana Med J. 2018;52(4):183-8.

23. Kirubel M, Abebaw D, Solomon A. Emergency Contraceptives: Knowledge and Practice towards Its Use among Ethiopian Female College Graduating Students. Int J Reprod Med. 2019;2019:1-8.

24. Bisrat Z, Bosena Tand F. Factors associated with utilization of emergency contraception among female students in Mizan-Tepi University, SouthWest Ethiopia. BMC Res Notes. 2015;8:817.

25. Kahsay G. Assesment of factors affecting emergency contraceptive use and prevalence of unwanted pregnancy among female students in aksum univerisity,addis ababa university college of health sciences school of public health; 2014.

26. Tewodros G, Tamene T, Tedla M, Wondimu A, Yeshialem K, Yosef L, Tilahun Sand C. Sexual experiences and emergency contraceptive use among female university students: a cross-sectional study at Wachamo University, Ethiopia. BMC Res Notes. 2015;8:112.

27. Habtamu A, Muleta M, Dube J. Knowledge, attitude, utilization of emergency contraceptive and associated factors among female students of Debre Markos higher institutions, Northwest Ethiopia. Fam Med Med Sci Res. 2014;3:4.
28. Nyambura MG, Kiarie JN, Orang'o O, Okube OT. Knowledge and utilisation of emergency contraception pills among female undergraduate students at the University of Nairobi, Kenya. Open J Obstetrics Gynaecol. 2017;7:9891005.

29. Byamugusha J, Mirembe F, Faxelid E, Gamzell K. Emergency contraception and fertility awareness among university students in Kampala, Uganda. Afr Health Sci. 2006;6:194-200.

30. Lee SW, Wai MF, Lai LY, Ho PC. Women's knowledge of and attitudes towards emergency contraception in Hong Kong: questionnaire survey. HKMJ. 1999;5:249-52.

31. Baafuor O, Fauster K. Knowledge and practices of emergency contraception among Ghanaian women. Afr J Reprod Health. 2011;15:147-52.

32. Yohannes A, Hedija Y, Abel F, Desta G. Prevalence of and factors associated with emergency contraceptive use among female undergraduates in Arba Minch University, southern Ethiopia. Int J Popul Growth. 2018;2018:1-8.

33. International Consortium for Emergency Contraception, Knowledge and Ever Use of Emergency Contraception in Latin America; Demographic and Health Survey Data, http://www.cecinfo.org/custom-content/uploads/2 012/12/Emergency-Contraception-in-Latin-America-Updated-11-27-2012.pdf Accessed 29 Aug 2014.

34. International Consortium for Emergency Contraception, Knowledge and Ever Use of Emergency Contraception in Europe and West Asia: Demographic and Health Survey Data, http://www.cecinfo.org/ customcontent/uploads/2014/03/Emergency-Contraception-in-Europe-andWestAsia-Updated-3-6-2014.pdf. Accessed 29 Aug 2014.

\section{Publisher's Note}

Springer Nature remains neutral with regard to jurisdictional claims in published maps and institutional affiliations.
Ready to submit your research? Choose BMC and benefit from:

- fast, convenient online submission

- thorough peer review by experienced researchers in your field

- rapid publication on acceptance

- support for research data, including large and complex data types

- gold Open Access which fosters wider collaboration and increased citations

- maximum visibility for your research: over $100 \mathrm{M}$ website views per year

At BMC, research is always in progress.

Learn more biomedcentral.com/submissions 